\title{
Influencing Factors Analysis for a Social Network Web Based Payment Service in China
}

\section{Yue Qu', Wenge Rong', Hui Chen', Yuanxin Ouyang', and Zhang Xiong ${ }^{1}$}

\author{
${ }^{1}$ Beihang University, School of Computer Science and Engineering, Beijing, China \\ quyuescse@buaa.edu.cn,w.rong@buaa.edu.cn, chenhui@buaa.edu.cn, oyyx@buaa.edu.cn, xiongz@buaa.edu.cn
}

Received 6 May 2017; received in revised form 29 September 2017; accepted 27 December 2017

\begin{abstract}
WeChat payment has recently become a popular mobile payment service in China by bundling with WeChat, the most popular social network service in China. It is interesting to investigate the reasons for its popularity. In this research, we applied the technology acceptance model to predict its acceptability and to identify variables attributing to its popularity. In addition to the primary explanatory variables, i.e., Perceived Ease of Use and Perceived Usefulness, the proposed framework is further extended to include the constructs of Social Interaction, Trust, Perceived Enjoyment and Use Context. The results indicated that the proposed model is able to explain the variance in a user's intention to use WeChat payment service. We hope this study can provide insights into understanding the adoption behaviour of socially aware mobile payment services.
\end{abstract}

Keywords: Mobile payment, WeChat, Technology acceptance model, Social interaction, Enjoyment, Trust 


\section{Introduction}

With the development of information technology, E-commerce has become an important part of modern economic industries and a magnificent growth has been observed in recent years. Many companies added E-commerce models to their operations and began innovative marketing and sales programmes via the Internet [3]. Moreover, handling financial transactions over the Internet has also greatly changed people's lifestyle, especially in the payment field.

Currently, online mobile payment has become one of the most important smartphone services in E-commerce [41], since mobile payments can lead to customer satisfaction [41], cost reduction [67], competitive advantage [25] and firm growth [71]. Mobile payment enables users to check account balances, transfer money, pay bills and conduct financial management at any time from anywhere [43]. Due to the advances of mobile Internet technology, and the rapid growth in the number of mobile users, making payments for goods, services, and bills via mobile devices is now playing an increasingly important role in our daily life [54]. For example, according to the data of the recently released report, The First Quarter of 2017 China's Third Party Mobile Payment Market Monitoring Report, China's third-party mobile payment market size of 18.80912 trillion yuan increased $46.78 \%$ [61].

Although Alipay is maintaining the largest mobile payment platform in the China, WeChat payment's market share has grown from $10 \%$ to $40 \%$ in the past three years, and it is close to that of Alipay. Tencent released WeChat payment in 2013 and bundled it with WeChat 5.0 so that users could simply click on the item links in the chat window to easily complete payments [8]. Moreover, through the red envelope promotion, WeChat payment attracted more than 8 million users, giving away 3 billion RMB on Chinese New Year's Eve in 2014 [9]. In 2017, the total number of WeChat red envelopes sent and received was 46 billion, up $43.3 \%$ from the previous year [60].

Compared with Alipay, WeChat payment is obviously different due to its social factors. WeChat is currently the most popular mobile social network service application in China. Its number of monthly active users has increased to 549 million, and WeChat payment users also reached 400 million by the end of the 1st quarter in 2015 [10]. Because online payments and using social networks are two of the most popular applications used daily on smartphones, the reasons for WeChat payment's wide usage deserves in-depth study [50]. There are many techniques in the literature that can be used to analyse such behaviour patterns, and the Technology Acceptance Model (TAM) [12] is one of the leading approaches. In recent decades, researchers have successfully applied the TAM and/or its extended models to explain the users' acceptance of many information technology-based systems [29]. In the TAM model, several determinant factors, e.g., usefulness, ease-of-use, etc., have been identified as the key influencers of the adoption of certain information systems [13].

In addition to these basic and fundamental factors, there are other variables that also contribute to the popularity of WeChat payment. Many previous studies on the reasons for using social network services and/or mobile payments have been conducted and they can be used to provide inspiration in the social mobile payment analysis. For example, a study by Zhou focuses on trust, flow and satisfaction on the intention to continue using mobile payments [74]. Li et al. studied the influencing factors and the influence mechanism that caused Chinese users to adopt mobile payments based on the TAM model [32]. For the social mobile payment, Guillen et al. analysed the effect of experience on users' acceptance of mobile payments in social networks with several machine learning methods [19].

In this research, we attempt to explain why people choose to use WeChat payment and to investigate the main determinants. Specially, we propose an extended TAM model and add several additional variables, such as social interaction, enjoyment, trust, etc., to enhance the understanding of people's intentions when using WeChat payment. The evaluation and validation of the proposed model is conducted by analysing questionnaires accumulated online, and several interesting findings are revealed.

The remainder of this paper is organized as follows. In section 2 we will introduce the background of the TAM model and social mobile payments. Section 3 will present the proposed extended TAM model and list the objectives and hypotheses. In section 4 we will present the data processing and discuss the experimental results. Finally, section 5 concludes the paper and suggests possible future work.

\section{Theoretical Foundations and Related Work}

In this section, we will briefly introduce the Technology Acceptance Model and also its variants in analysing adoption of information systems. We also further present the basic challenges and analysis in social network based payment.

\subsection{Technology Acceptance Model}

In the area of information systems, there is a need for researchers to understand the reasons behind the users' actual usage of IT systems. To solve this problem, many technologies have been proposed, e.g., Technology Acceptance Model (TAM) [12], Unified Theory of Acceptance and Use of Technology (UTAUT) [5], Task-Technology 
Fit (TTF) [20], etc. The comparison of several common user behaviour analysis models is shown in Table 1. Among these approaches, the Technology Acceptance Model (TAM) has been regarded as the most robust, parsimonious and influential model for making predictions on acceptance and use of new information technologies and systems [47]. During the last decades, TAM has been successfully applied to many research domains and related applications, such as education [14], finance [59], E-Commerce [46], etc. These applications have demonstrated TAM's capacity and validity in identifying the features that drive success for information systems and their adaptability to work-related needs.

Table 1: The Comparison of models

\begin{tabular}{|c|c|c|c|c|}
\hline Model & Basic Variables & $\begin{array}{l}\text { Scope of } \\
\text { Application }\end{array}$ & Advantage & Disadvantage \\
\hline $\begin{array}{l}\text { Technology Acceptance } \\
\text { Model (TAM) [12] }\end{array}$ & $\begin{array}{l}\text { Perceived Ease of } \\
\text { Use } \\
\text { Perceived } \\
\text { Usefulness } \\
\text { Behaviour } \\
\text { Intention }\end{array}$ & $\begin{array}{l}\text { APP } \\
\text { New Technology } \\
\text { Promotion }\end{array}$ & $\begin{array}{l}\text { Wide Applicability } \\
\text { Expansibility } \\
\text { Technical } \\
\text { Pertinence } \\
\text { Hierarchical } \\
\text { Structure }\end{array}$ & $\begin{array}{l}\text { Narrow Factor } \\
\text { Range }\end{array}$ \\
\hline $\begin{array}{l}\text { Unified Theory of } \\
\text { Acceptance and Use of } \\
\text { Technology (UTAUT) [5] }\end{array}$ & $\begin{array}{l}\text { Performance } \\
\text { Expectancy } \\
\text { Effort Expectancy } \\
\text { Social Influence } \\
\text { Facilitating } \\
\text { Conditions }\end{array}$ & $\begin{array}{l}\text { New Technology } \\
\text { Comprehensive } \\
\text { Evaluation }\end{array}$ & $\begin{array}{l}\text { Multi-model } \\
\text { Integration } \\
\text { Factor } \\
\text { Comprehensive }\end{array}$ & $\begin{array}{l}\text { Factor } \\
\text { Classification } \\
\text { Difficulty } \\
\text { Non-functional } \\
\text { Weakness }\end{array}$ \\
\hline $\begin{array}{l}\text { Task-Technology Fit } \\
\text { (TTF) [20] }\end{array}$ & $\begin{array}{l}\text { Task } \\
\text { Characteristics } \\
\text { Technology } \\
\text { Characteristics } \\
\text { Task-Technology- } \\
\text { Fit } \\
\text { Performance } \\
\text { Impact }\end{array}$ & $\begin{array}{l}\text { Information } \\
\text { Technology } \\
\text { Task-Technology } \\
\text { Fit }\end{array}$ & $\begin{array}{l}\text { Professional } \\
\text { Pertinence }\end{array}$ & $\begin{array}{l}\text { Underpopulation } \\
\text { Weak } \\
\text { Subjective } \\
\text { Factor }\end{array}$ \\
\hline
\end{tabular}

In the earliest TAM model, it is argued that the Actual System Use is predictable by User Motivation, which is also directly influenced by external variables, i.e., system's features, capabilities and so on [12]. It is further suggested that User Motivation consists of two influential factors, i.e., Perceived Ease of Use and Perceived Usefulness, which can explain the Actual System Use, as shown in Figure 1. In this TAM model, the Behaviour Intention, which is influenced by Perceived Usefulness and Perceived Ease of Use, is the major determinant for a user to accept or reject a certain system. Furthermore, Perceived Usefulness and Perceived Ease of Use will be affected by several external stimuli. Davis finally hypothesized that Perceived Usefulness and Perceived Ease of Use are the most important beliefs for a user to make the decision of acceptance of the system or not. Since the TAM model was first proposed, it has been gradually refined and several other variables are included in the original TAM model, such as Behavioural Intention [13]. Because the TAM model has evolved into a leading model for predicting and explaining information systems acceptance, it is believed the TAM model is also appropriate to analyse the social network based mobile payment tool's popularity.

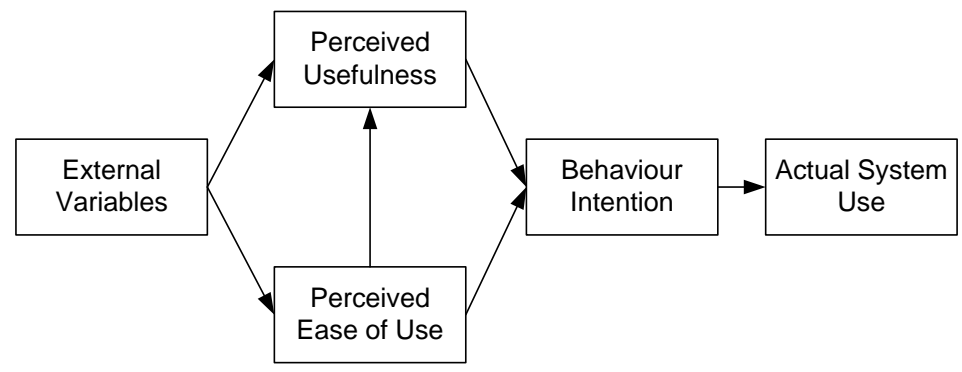

Figure 1: Conventional technology acceptance model

\subsection{Social Network Based Mobile Payment Analysis}

With the development of the Internet and E-commerce, online payment has rapidly developed and has become an important part of E-commerce since it makes online trading more convenient and decreases the operational risks [45]. Many studies have been conducted to analyse the factors influencing online payment to further improve its 
performance. For example, He et al. studied a basic online payment model and the relationship between online payments with electronic credit cards, electronic cash and electronic checks. They found that the current payment was still a weak link because of the risks to security and credit [23]. In the studies by Gao and Guo, they discussed the operational risk of e-banking in China and then suggested that the banks should prepare sufficient cash every year for the operational risk, which was calculated from their model [17].

Currently, online payment services are not only used via the computer. They are also becoming popular on mobile devices, especially on smartphones. Mobile online payments increase the convenience of E-commerce for people trade anywhere they want. Moreover, with the privacy of mobile phones, people began trusting the payment services more [40]. From the studies by Kim et al., they combined users and systems together to discuss the intention factors for using mobile online payments. Interestingly, they found that the main factors were different between early adopters and late adopters because of the need for creativity [26]. Mallat concluded that the mobile payment advantages were affected by the mobile technology, the use circumstance and situational factors. Moreover, he emphasized the importance of compatibility and trust factors on the diffusion of a new payment system [38]. Similarly, Yang et al. designed a new mobile payment pattern by establishing a trusted relationship layer by layer and advocating a stratified extension to supply a better co-ordination channel and security control mechanisms [69]. Schierz et al. conducted a survey and suggested that compatibility, individual mobility, and subjective norms were the three most important factors influencing consumer acceptance of mobile payment services [53].

Apart from mobile payments, we also focus on another field, social network services on mobile devices, such as Facebook, Twitter, WeChat and others. With the high-speed development of mobile Internet, mobile social network platform oriented applications have received rapid and diverse promotion. Many studies investigating how people use social network have been conducted. For example, Xie conducted an experimental study on teenagers and found that mobile-based personal talking acts as a moderating role in SNS (social network sites) [66]. Klein et al. summarized that the personal activity status of key members was highly correlated with their structural centrality measures. Therefore, friends might always make similar choices and behave similarly [27]. Zhang et al. designed the MMSN architecture, including privacy of the content query, trust-based service evaluation, and privacy-preserving content filtering, to decrease the conflict between sharing and privacy [73].

From the discussion above, it is clear that mobile payment services and social network services are both important products on mobile devices and change our lives every day. If we combine them, what will happen? The WeChat Payment is a good example of this idea and has attained initial success. In fact, social networks are very useful when generalizing services, including E-commerce services. Singh and Jasmine supplied a new view regarding mobile phones, suggesting that it is a powerful device for uploading and consuming content. They argued that both personal interest and social networks would influence mobile services, including payment services [55]. LiebanaCabanillas et al. supplied a modification of the classical technological acceptance models (TRA and TAM) to analyse users' acceptance of mobile payments in the virtual social network. They discovered that the acceptance process of online payment had a large influence on the diffusion of mobile payment systems on the virtual social networks (VSN) [33].

\section{Methodology and Hypotheses}

A social network based on a mobile payment platform is a new type of service for people to conduct financial transactions on their mobile phones. In China, though Alipay is currently the most popular mobile online payment service, when WeChat released its WeChat payment service, the new service immediately and quickly seized the market and increasingly developed [60]. One of the influential reasons is that WeChat is the most popular mobile app based on social network service and WeChat payment is integrated into its main interface [24]. Different from other online payments, financial activities between friends occupy a large proportion of WeChat payment transactions. Therefore, the biggest difference between Alipay and WeChat payment is the social perspective.

In this research, we will use WeChat payment as the case study to examine the relationship between a social network and online payments. This paper proposes an extended TAM model with some additional factors to perform the analysis. The basic TAM model includes three factors, which include the perceived ease of use (PEOU), perceived usefulness (PU), and behaviour intention (BI) [12]. Moreover, since trust is the foundation of financial transactions, ensuring the financial security is very important to people's choices regarding online payments [75]. Different from other online payment services, WeChat payment applies some interesting activities to improve the users' enthusiasm [72]. Therefore, perceived enjoyment (PE) is a new and important factor added to the model. As a mobile service, use context (UC) is also a necessary factor that should be added in the model to show the effect of the use situation and technology support [16]. Furthermore, considering the advantage of WeChat platform in social activities, we added social interaction (SI) to the proposed model. The conceptual framework is depicted in Figure 2 and all factors and related hypotheses will be described in detail in following subsections. 


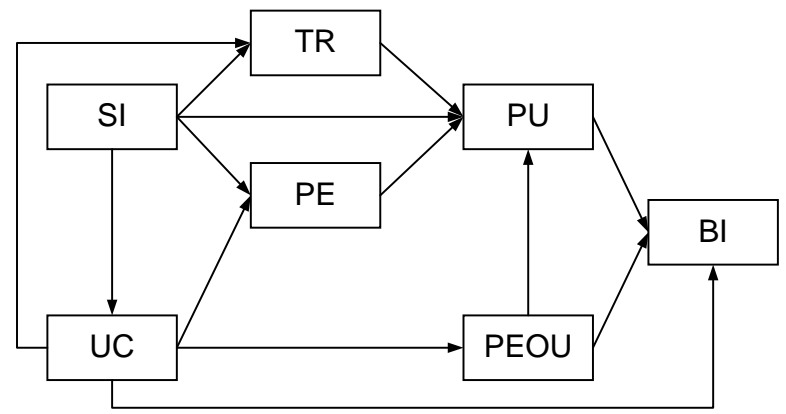

Figure 2: Path model

\subsection{TAM}

Davis argued that the core constructs of the TAM model are perceived usefulness (PU) and Perceived ease of use (PEOU) [12]. Both constructs have been consistently shown to have a significant impact on technology adoption [12]. Moreover, tracing the impact of external factors on internal beliefs, attitudes, and intentions is the key aim of the TAM model. Therefore, to fit the development of social network based mobile payments, we developed new meanings for the basic factors of the TAM model.

PU is defined as the degree to which a technology is perceived as providing benefits in performing certain activities [13]. Based on the function of WeChat payment, PU can be defined as various innovations since it reflects the influence on our lives and habits by the service.

PEOU is defined as the extent to which a technology is perceived as being easy to understand and use [13]. With the user experience, in this experiment, PEOU stands for easy-learning and easy-operating [1]. We hypothesized that both of PU and PEOU reflect the users' behaviour intention. PEOU also indirectly influences intention through perceived usefulness. Consequently, the following hypotheses are proposed:

\section{H1. Perceived usefulness (PU) positively influences the behaviour intention (BI) to use WeChat payment.}

H2. Perceived ease of use (PEOU) positively influences the behaviour intention (BI) to use WeChat payment.

H3. Perceived ease of use (PEOU) positively influences the perceived usefulness (PU) of using WeChat payment.

\subsection{Trust}

Trust is the most important foundation for financial transactions, especially in the E-commerce area [18]. Since there is high uncertainty and perceived risk associated with using mobile devices, we should consider trust (TR) as an important factor being integrated into the proposed model. In E-commerce applications, the trust degree mainly depends on the reliability [68] and the technology security [48] of the system. Moreover, the relationship and credit records of the participants will also affect the trust degree. When using the WeChat payment service, the users will be asked to add their personal information and credit card information. Users may worry about privacy risks, financial risks, time risks, etc. As a result, the greater the perceived risk, the lower the consumer's trust in WeChat payment [6]. Furthermore, trust also depends on the reliability of the users' financial partners [28]. Since trust may change the user's awareness of a mobile payment service and judgement on the usefulness [63], we formed the following hypothesis:

H4. Trust (TR) positively influences the perceived usefulness (PU) of using a social network mobile payment.

\subsection{Perceived Enjoyment}

Perceived enjoyment (PE) is a new consideration for E-payments since it has an extremely important influence on social network services. PE is a typical intrinsic motivator, which will play an important role in computer usage [62]. For example, when Wang et al. studied the students' use of blogging, they considered perceived enjoyment (PE) as the most important factor [62]. Moreover, if the users can obtain enjoyment from one service, their attitude towards adoption will be positive. If there are two similar services, people always prefer the one that is enjoyable [37]. Combined with the social network service, perceived enjoyment (PE) is a promotion of the connection initiative.

In this research, perceived enjoyment $(\mathrm{PE})$ reflects the pleasant experience of using the service, especially with some interesting functions and activities. One of the most interesting and popular activities of WeChat payment is the new year red envelope. This activity is born from a traditional practice of the Chinese Spring Festival. Chinese people normally give a red envelope to children to show best wishes for the new year. Usually, they place some 
money in the red envelopes and send them when they celebrate the new year together. From 2014, WeChat payment released a function allowing people to send red envelopes to others by using WeChat payment. With this activity, users could send red envelopes to special people online with a message. Moreover, they could send a large red envelope to many friends, and friends could randomly receive some money. This activity spread quickly among Chinese people. Friends used it for enjoyment and sent wishes. Therefore, we made the following hypothesis:

H5. Perceived enjoyment (PE) positively influences the perceived usefulness (PU) of using a social network mobile payment.

\subsection{Use Context}

The Use Context (UC) is the environment where the technology is used and can be further divided into the hardware environment and the software situation [42]. The hardware environment stands for the time and space where a particular action is taken. The software environment includes mobility and compatibility [26]. In fact, many studies have examined the use context (UC) factor effect on mobile services. For example, Mallat et al. noted that the mobility, including time and place independent service access, could reduce the limitations of the devices and played an important role in the promotion of mobile services [39]. In this research, UC is considered the use environment and technology of mobile phones, which is changing quickly through the updates to smartphone technology. The software situation relates to the lifestyles of users and tends to vary regarding the unique nature of the mobile service in question [34]. In this research, it may include the context of a daily habit when we engage in E-commerce transactions, the specific functions offered by the service, etc.

As many contextual situations may reflect the user's experience with social network mobile payments, our study focused on multiple WeChat payments using situations which affect users' perceived experiences. For example, sometimes a user needs to make a transaction urgently but does not have cash and no ATM machine is available. $\mathrm{He}$ can use the mobile payment to solve this problem without the limitations of external devices. This situation may improve the user's experience of the convenience of the service and directly affect a user's behaviour.

It is the same as some other users' perceived experiences. Lubomski and Krawczyk used the Trustand Contextoriented Role Based Access Control (TCoRBAC) model to find the relationship between contextual items and user trust levels regarding the Internet system [35]. Users' trust of online payment depends on the economic security protection level, which is included in the software environment of the use context. Additionally, a safe operating environment is very important to avoid the risk of revealing a user's information. Moreover, a comfortable user experience regarding mobility and compatibility will influence the user's enjoyment experience. Hence, the hypothesis is posited as follows:

H6. Use context (UC) positively influences the perceived ease of use (PEOU) of using a social network mobile payment.

H7. Use context (UC) positively influences trust (TR) when using a social network mobile payment.

H8. Use context (UC) positively influences the perceived enjoyment (PE) of using a social network mobile payment.

H9. Use context (UC) positively influences the behaviour intention (BI) on WeChat payment.

\subsection{Social Interaction}

Social interaction is very common in our daily life. In the study by Sailer and McCulloh [51], they gathered two fields (space syntax and social network analysis) to research the relationships in social networks. They found that the likelihood of two people interacting depended not only on the structural effects within networks but also on the physical distance separating the actors. Moreover, the mobile social network decreases the distance anytime and anywhere [2]. In this research, we used the case of WeChat payment, which offers a wide social network platform to perform traditional E-commerce. We proposed that social interaction was a necessary factor in the extended TAM model and affected other factors. First, the social connections between a payer and a payee may determine the trust of financial transactions [75].

For example, when people use WeChat payment to trade with others, they have always already been connected with the trading persons by WeChat, and they can save the communication information. Moreover, most contractors in WeChat are real friends, so they trust each other more [70]. Therefore, we assume that social interaction (SI) is connected with trust (TR). Additionally, recommendations and interaction with friends may affect the users' use context. For example, when buying something together with friends, people generally choose the same payment method. Therefore, we think that social interaction (SI) is connected with the use context (UC).

If someone participates in some social activities on the mobile payment service with his friends, the experience can influence his basic awareness of the service, such as the perceived enjoyment (PE) and perceived usefulness (PU). The new year red envelope promotion is a typical activity where friends use WeChat payment together. WeChat 
payment also offered some other activities, such as a sharing coupon, which is also very interesting and popular. The sharing coupon is an activity where users can share an online coupon in their WeChat Friends Circle (this is a platform similar to Facebook to share information with friends). This activity increases the frequency of using WeChat payment and improves the connections in the users' life. Therefore, we assume that social interaction (SI) is connected with perceived enjoyment (PE) and perceived usefulness (PU). For the above reasons, we propose the following hypotheses:

\section{H10. Social interaction (SI) positively influences trust (TR) of a social network mobile payment.}

H11. Social interaction (SI) positively influences the perceived enjoyment (PE) of a social network mobile payment.

H12. Social interaction (SI) positively influences the use context (UC) of a social network mobile payment.

H13. Social interaction (SI) positively influences the perceived usefulness (PU) of using a social network mobile payment.

\section{Analysis and Results}

In this section, we will illustrate the experimental study to validate the propose hypotheses, including the two-step data collection, factor analysis and discussion of the experimental result. The limitation of this research is also elaborated in this section.

\subsection{Data Collection}

This experiment is divided into a trial investigation and formal research. In the trial investigation, we collected 179 groups of data, among which 101 groups of data were useful. After carefully analysing the test data, the final questionnaire includes 35 questions, as shown in Table 2. The final questionnaire consists of two parts. The first part includes the basic personal information questions and the second part includes questions regarding the experience of using WeChat payment. There are 9 questions in the first part, which cover the gender, age and the basic user situation regarding the mobile phone, WeChat, and WeChat payment [24]. There are 26 questions in the second part. According to the thirteen hypotheses, the questionnaire consists of three items to collect feedback from the users [7]. In addition, there are 3 reverse questions that are opposite to TR1, PE1 and PEOU2 in the questionnaire to determine whether the respondent is reading and answering the questions accurately. Each question was measured on a 7-point Likert scale from strongly agree (7) to strongly disagree (1), which has shown good internal consistency in most studies [65].

Table 2: Questionnaire

\begin{tabular}{|l|l|}
\hline Items & Questions \\
\hline SI1 & Many of my friends use WeChat payment. \\
SI2 & I like to join in on some online financial activities with my friends on WeChat payment. \\
SI3 & I enjoy sharing online coupon information with friends through WeChat payment. \\
SI4 & Sharing online coupons through WeChat payment is advantageous to me and others. \\
\hline TR1 & WeChat payment always provides reliable financial services. \\
TR2 & The risk of abuse of usage information is low when using WeChat payment. \\
TR3 & The risk of abuse of billing information is low when using WeChat payment. \\
\hline PE1 & I think that using WeChat payment is enjoyable. \\
PE2 & I have fun interacting with WeChat payment. \\
PE3 & The activities in WeChat payment, such as red envelope, are interesting. \\
\hline UC1 & I use WeChat payment because it can make the transaction easier. \\
UC2 & I think WeChat payment is easily accessible and portable. \\
UC3 & I believe WeChat payment is compatible with other mobile services. \\
\hline PEOU1 & It is easy for me to perform the actions required to use WeChat payment. \\
PEOU2 & Skilfully using WeChat payment is easy for me. \\
PEOU3 & I expect that my interaction with WeChat payment will be clear and easy. \\
PEOU4 & I expect that learning how to use WeChat payment will be easy for me. \\
\hline PU1 & WeChat payment improves my living and working efficiency. \\
PU2 & Using WeChat payment makes it easier for me to conduct financial transactions. \\
PU3 & In some special cases, WeChat payment is more useful than traditional payment methods. \\
\hline BI1 & I expect my use of WeChat payment to continue in the future. \\
BI2 & Now I always pay for purchases by using WeChat payment. \\
BI3 & I recommend WeChat payment to others who intend to use mobile payment. \\
\hline
\end{tabular}


Initially, we obtained 420 groups of data. To improve the data's validity, we eliminated 1) the responses of the informants who never used the WeChat payment service; 2) insincere responses through data filtering using the three reverse questions; 3) insincere responses that look similar to Straight-Line answers or Wave answers [7]. The questionnaires screening information is shown in Table 3. In the field of human-computer interaction for qualitative analysis, if the size of the data set is 10 times the number of items, then it can be viewed as an effective dataset [31]. In this experiment, we collected 320 valid questionnaire responses so we regard this as an effective data set. Finally, the data is filtered to perform the experiment and the sample distribution is shown in Table 4. In 2015, WeChat's market report showed that more than $80 \%$ of WeChat users were between the ages of 18 and 35 . Therefore, the questionnaire respondents in this study are mainly young users of WeChat payment. The data collection method of this study is field investigation. Researchers randomly invited users to fill out the questionnaire on the university campuses, effectively protecting the universality and authenticity of the data.

Table 3: Data filtering results

\begin{tabular}{|l|l|}
\hline Items & Number \\
\hline Total response number & 420 \\
\hline Response number eliminated by reason 1 & 24 \\
\hline Response number eliminated by reason 2 & 30 \\
\hline Response number eliminated by reason 3 & 46 \\
\hline
\end{tabular}

Table 4: Question standardization and reliability analysis

\begin{tabular}{|l|l|l|l|}
\hline Item & Demographic & Frequency & Percentage \\
\hline Gender & Male & 174 & 54.38 \\
& Female & 146 & 45.62 \\
\hline Age & $<18$ & 4 & 1.25 \\
& $19-25$ & 201 & 62.81 \\
& $26-35$ & 81 & 25.31 \\
& $36-45$ & 21 & 6.56 \\
& $>45$ & 13 & 4.06 \\
\hline Mobile Phone Operating System & IOS & 36 & 11.25 \\
& Android & 274 & 85.63 \\
& Windows Phone & 6 & 1.88 \\
& else & 4 & 1.24 \\
\hline
\end{tabular}

\subsection{Exploratory Factor Analysis}

It is necessary to conduct an exploratory factor analysis to validate if the sample data is acceptable as the experimental basis. In this research, first, we used the exploratory factor analysis method to determine the basic structure of the influencing factors of WeChat payment user behaviour intention and solve the problem of the strong correlation between variables in a multivariate statistical analysis. Exploratory factor analysis is mainly used to determine the influence observation variable factors, the degree of correlation between each factor and each observed variable, using factor loading intuitively to infer the factor structure of the data [21]. The analysis results are shown in Table 5.

Table 5: Results of factor analysis

\begin{tabular}{|c|c|c|c|c|c|c|c|c|}
\hline Dimensions & Items & Mean & $\begin{array}{l}\text { Std. } \\
\text { Deviation }\end{array}$ & Loading & $\begin{array}{l}\text { Variance } \\
\text { Extracted }\end{array}$ & AVE & $\begin{array}{l}\text { Cronbach's } \\
\text { Alpha }\end{array}$ & CR \\
\hline SI & $\begin{array}{l}\text { SI1 } \\
\text { SI2 } \\
\text { SI3 } \\
\text { SI4 }\end{array}$ & $\begin{array}{l}5.302 \\
4.819 \\
5.322 \\
5.422 \\
5.644\end{array}$ & $\begin{array}{l}1.921 \\
1.403 \\
1.494 \\
1.429\end{array}$ & $\begin{array}{l}0.612 \\
0.702 \\
0.696 \\
0.797\end{array}$ & $\begin{array}{l}0.628 \\
0.618 \\
0.668 \\
0.685\end{array}$ & 0.50 & 0.722 & 0.797 \\
\hline TR & $\begin{array}{l}\text { TR1 } \\
\text { TR2 } \\
\text { TR3 } \\
\end{array}$ & $\begin{array}{l}4.465 \\
4.466 \\
4.363 \\
4.566 \\
\end{array}$ & $\begin{array}{l}1.527 \\
1.492 \\
1.598 \\
\end{array}$ & $\begin{array}{l}0.767 \\
0.801 \\
0.721 \\
\end{array}$ & $\begin{array}{l}0.690 \\
0.718 \\
0.684 \\
\end{array}$ & 0.58 & 0.734 & 0.807 \\
\hline $\mathrm{PE}$ & $\begin{array}{l}\text { PE1 } \\
\text { PE2 } \\
\text { PE3 }\end{array}$ & $\begin{array}{l}5.608 \\
5.041 \\
5.831 \\
5.953\end{array}$ & $\begin{array}{l}1.654 \\
1.356 \\
1.339 \\
\end{array}$ & $\begin{array}{l}0.702 \\
0.793 \\
0.709 \\
\end{array}$ & $\begin{array}{l}0.612 \\
0.726 \\
0.612\end{array}$ & 0.54 & 0.702 & 0.779 \\
\hline UC & $\begin{array}{l}\text { UC1 } \\
\text { UC2 } \\
\text { UC3 }\end{array}$ & $\begin{array}{l}5.646 \\
5.738 \\
5.916 \\
5.284\end{array}$ & $\begin{array}{l}1.279 \\
1.151 \\
1.450\end{array}$ & $\begin{array}{l}0.742 \\
0.793 \\
0.578\end{array}$ & $\begin{array}{l}0.693 \\
0.758 \\
0.561\end{array}$ & 0.51 & 0.757 & 0.750 \\
\hline
\end{tabular}




\begin{tabular}{|c|c|c|c|c|c|c|c|c|}
\hline \multicolumn{9}{|c|}{ Table 5: continuation } \\
\hline PEOU & $\begin{array}{l}\text { PEOU1 } \\
\text { PEOU2 } \\
\text { PEOU3 } \\
\text { PEOU4 }\end{array}$ & $\begin{array}{l}6.177 \\
6.238 \\
6.188 \\
6.378 \\
5.903\end{array}$ & $\begin{array}{l}2.528 \\
1.210 \\
1.049 \\
1.339\end{array}$ & $\begin{array}{l}0.708 \\
0.805 \\
0.733 \\
0.620\end{array}$ & $\begin{array}{l}0.601 \\
0.712 \\
0.578 \\
0.523\end{array}$ & 0.52 & 0.732 & 0.810 \\
\hline PU & $\begin{array}{l}\text { PU1 } \\
\text { PU2 } \\
\text { PU3 }\end{array}$ & $\begin{array}{l}5.739 \\
5.697 \\
5.906 \\
5.613\end{array}$ & $\begin{array}{l}1.350 \\
1.345 \\
1.486\end{array}$ & $\begin{array}{l}0.705 \\
0.683 \\
0.742\end{array}$ & $\begin{array}{l}0.601 \\
0.645 \\
0.654\end{array}$ & 0.51 & 0.732 & 0.753 \\
\hline $\mathrm{BI}$ & $\begin{array}{l}\mathrm{Bl} 1 \\
\mathrm{Bl} 2 \\
\mathrm{Bl} 3\end{array}$ & $\begin{array}{l}4.585 \\
4.078 \\
4.678 \\
5.000\end{array}$ & $\begin{array}{l}1.849 \\
1.655 \\
1.689\end{array}$ & $\begin{array}{l}0.646 \\
0.788 \\
0.714\end{array}$ & $\begin{array}{l}0.576 \\
0.693 \\
0.627\end{array}$ & 0.52 & 0.717 & 0.761 \\
\hline
\end{tabular}

First, in this research, we use Cronbach's alpha coefficient to test the internal consistency of the data [64]. We calculated the Cronbach's alpha coefficient of each of the hypothetical factors and all the data, respectively. The results are listed in Table 5, where the total Cronbach's alpha coefficient is 0.872 and all the coefficients of each factor are greater than 0.700 , which means the collected data meet the general requirement that the total Cronbach's alpha coefficient should be greater than 0.8 , and the coefficient of each element should be greater than 0.7 [64]. We also test the factor loading of each item and the AVE of each factor. The results all exceed 0.5, which indicates convergent validity [22]. All the composite reliability (CR) values are over 0.7 , which means the reliability of each factor is satisfied [39]. From the exploratory factor analysis, it is concluded that the collected data is satisfactory for conducting further analysis.

Second, we need to conduct validity analysis for the construct validity of the assessment. Construct validity is mainly used to measure questionnaires where the scales can be measured by the level of theoretical assumptions [52]. Construct validity includes two categories, i.e., convergent validity and differentiate validity. We used Bartlett's test of sphericity and the Kaiser-Meyer-Olkin (KMO) measure of sampling adequacy to measure the collected data. The result is shown in Table 6 , which indicates the suitability of the conducting factor analysis, with statistics of X2 (253) $=2366.528$ (Sig. < .000). Based on the commonly used KMO measures by Kaiser, a value over 0.7 will be acceptable and is better the closer it is to 1 . The $\mathrm{KMO}$ measure $=0.860$, which means the collected data has valid convergent validity. Sig. $<.000$ means that the data has distinction validity [64].

Table 6: KMO and bartlett testing

\begin{tabular}{|l|l|l|}
\hline \multicolumn{2}{|l|}{ Kaiser-Meyer-Olkin } & .860 \\
\hline Bartlett Testing & $X^{2}$ & 2366.528 \\
& $\mathrm{df}$ & 253 \\
& Sig. & .000 \\
\hline
\end{tabular}

Third, we also need to determine if the distinction validity of the data is reasonable or not. In Table 7, the results shown at the diagonal are the square root of the average variance extracted (AVE) value for each factor, which are greater than the correlation between the different factors [36].

Table 7: Intercorrelations between factors

\begin{tabular}{|l|l|l|l|l|l|l|l|}
\hline & SI & TR & PE & UC & PEOU & PU & BI \\
\hline SI & .707 & & & & & & \\
\hline TR & .342 & .762 & & & & & \\
\hline PE & .374 & .264 & .735 & & & & \\
\hline UC & .403 & .393 & .459 & .714 & & & \\
\hline PEOU & .231 & .241 & .232 & .364 & .721 & & \\
\hline PU & .251 & .337 & .377 & .451 & .399 & .714 & \\
\hline BI & .283 & .349 & .303 & .479 & .173 & .503 & .721 \\
\hline
\end{tabular}

\subsection{Findings}

In the last section, we used the exploratory factor analysis method to analyse the data without theoretical support to obtain the factors. The next step is to perform further tests with the confirmatory factor analysis. The main purpose of confirmatory factor analysis is to test, before defining the factors, if the model fits the actual data, and to test whether the observed variable factor and factor of the load based on the theory and expectations. Therefore, after conducting 
exploratory factor analysis, we need to use the confirmatory factor analysis method to test the proposed hypothesis model. The core work of confirmatory factor analysis is to carry out the structural equation model (SEM) calculation. The structural equation model is a statistical mathematical tool for analysing the relationship between variables. The main calculation idea is to design a model reflecting the relationship of variables based on the exploratory factor analysis based on the factor structure and path assumption. The researchers will analyse the data import model to verify the calculation and determine whether the model is reasonable and acceptable according to the fitting index [4]. Confirmatory factor analysis results are normally divided into two parts, i.e., path analysis and fit test of the model. Path analysis is used to estimate the relationship between the variables in the proposed model and determine which variables are cared for by the users. We used the statistical tools to add the data to the hypothesis model and calculate the weight coefficients of the hypothetical path. The result is shown as in Table 8 and Figure 3, where we can judge whether the path is accepted by the result of the weight coefficients [58]. Moreover, the coefficients also reflect the strength of the causal relationships [58].

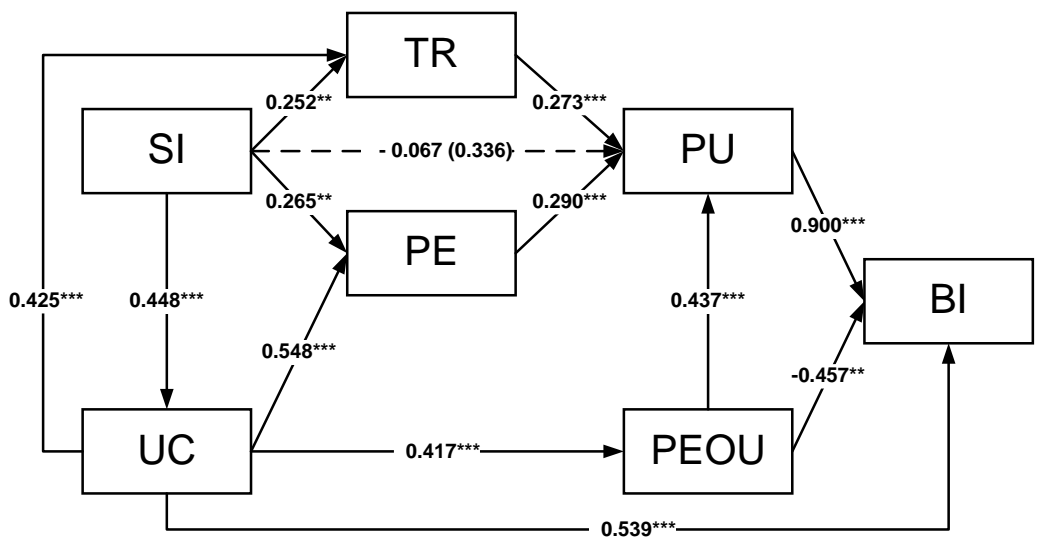

Figure 3: Path verification

Table 8: Analysis of the significance of the path coefficient

\begin{tabular}{|c|c|c|c|}
\hline Path & Standardized Estimate & C.R. & Support(Y/N) \\
\hline $\mathrm{H} 1: \mathrm{PU}->\mathrm{BI}$ & $0.900^{\star \star \star}$ & 5.568 & Y \\
\hline H2: PEOU->BI & $-0.457^{* *}$ & -3.164 & $\mathrm{Y}$ \\
\hline H3: PEOU $\rightarrow P U$ & $0.437^{\star \star \star}$ & 4.958 & Y \\
\hline H4: TR->PU & $0.273^{\star \star \star}$ & 3.375 & $\mathrm{Y}$ \\
\hline H5: PE->PU & $0.290^{\star \star \star}$ & 3.814 & Y \\
\hline H6: UC->PEOU & $0.417^{* * *}$ & 5.843 & Y \\
\hline H7: UC->TR & $0.425^{\star \star *}$ & 4.048 & Y \\
\hline H8: UC->PE & $0.548^{\star \star \star}$ & 5.031 & Y \\
\hline H9: UC->BI & $0.539^{\star \star \star}$ & 4.423 & $Y$ \\
\hline $\mathrm{H} 10: \mathrm{SI}->\mathrm{TR}$ & $0.252^{* *}$ & 2.824 & $\mathrm{Y}$ \\
\hline $\mathrm{H} 11: \mathrm{SI}->\mathrm{PE}$ & $0.265^{\star *}$ & 2.962 & Y \\
\hline H12: SI->UC & $0.448^{\star \star \star}$ & 6.239 & Y \\
\hline H13: SI->PU & $-0.067(0.336)$ & -0.963 & $\mathrm{~N}$ \\
\hline
\end{tabular}

The next step of the confirmatory factor analysis is calculating the model fit indexes to determine whether the model fit is good. In SEM, many fit indexes as goodness-of-fit exist to appraise an entire model, such as X2, CFI, AGFI and RMSEA [58]. They view different ways that the model fits and can affect each other. The X2 is an especially important index of goodness-of-fit because it is the foundation of many indexes and can be used to test the null hypothesis. In this paper, we judge the model fitness by the following indexes, X2, GFI, AGFI, RMSEA, CFI, and NFI. The results are shown in Table 9. Since all the fit indexes meet the requirements, it is concluded that the proposed model's fitness is adequate [58]. 
Table 9: Fit Indexes for the measurement

\begin{tabular}{|l|l|l|}
\hline & Results & Recommended Criteria \\
\hline X2 & 1.616 & $<5.0$ \\
\hline GFI & 0.914 & $>0.85$, close to 1 \\
\hline AGFI & 0.890 & $>0.80$, close to 1 \\
\hline RMSEA & 0.044 & $\leq 0.06$, close to 0 \\
\hline CFI & 0.939 & $>0.90$, close to 1 \\
\hline NFI & 0.856 & $>0.85$, close to 1 \\
\hline
\end{tabular}

\subsection{Discussions}

This study developed a theoretical framework based on the TAM model and discussed the structural equation modelling analysis of a social network mobile payment service adoption. In the experimental study, the proposed hypotheses are evolved through the users' feedback regarding WeChat payment. The findings in this study provided empirical support for the proposed model. The results clarified our understanding of the attitudes and intentions that people have towards using social network mobile payment services and helped reveal the implications for the successful implementation of WeChat payment in China. The measurement of this study provided a good fit to the data, thereby lending support to the proposed model. Overall, the results show that the proposed model can accurately describe the intentions of users to use a mobile social payment service.

From the experimental study, it is found that social interaction does influence the use context, perceived enjoyment and trust. In fact, social interaction is the most typical difference between WeChat payment and other mobile payment services. To use the social relationship offered by WeChat, WeChat payment has released many activities to strengthen the interaction between users and their friends. For example, the interactive games among friends, such as the red envelope have attracted millions of people to join this platform. Benefiting from these activities, WeChat payment provides a new platform for users to communicate with each other and strengthen the relationships among them. This result corroborates the previous research on social interaction and perceived enjoyment, that the interactions between friends can greatly enhance the entertainment of the user experience [57] and increase the use of WeChat payment. If people get red envelopes or coupons from friends, they will also consider using WeChat payment for some situation where they used to use other online payment services. At the same time, social interaction also shows the significant role of trust. Trust is the foundation of financial transactions and heavily depends on the social interactions of the partners in the transactions [49]. When people engage in online financial transactions, they prefer to interact with their friends, who they trust more than strangers [30]. Therefore, it is concluded that the relationship of friends strengthens the user's trust of WeChat payment.

The experimental results show that PU of $\mathrm{BI}$ has a strong positive effect and that PEOU has a weak negative effect. However, PEOU on PU has an obvious positive effect. This conclusion does not indicate that the basic TAM model is not established in the WeChat payment user behaviour analysis, but reveals some interesting phenomena. First, PEOU has slightly negative effect on BI. In this article, through analysis of the PEOU experience score data distribution and random review, users of the usability evaluation of a smaller range of the different users gave a higher score of ease of use. Considering the convenience of smartphones and mobile phone application service, the rapid development of ease of use has become a basic characteristic of mobile applications. In that way, the user experience on the differences between applications is not big, thus it no longer has an obvious effect on the user's choice. At the same time, WeChat payment is an Internet financial tools, and an operating process that is too convenient can cause the user to distrust the information security protection, and the users' willingness to use the service will be reduced [16]. Therefore, it is reasonable that PEOU for BI shows a weak negative correlation. However, that does not mean that if WeChat payment uses tedious steps it will promote the users' intention, because PEOU still has a positive effect on PU. The PU of BI has a strong positive role in promotion. Therefore, understanding the perceived ease of use of WeChat payment users is a key concern of WeChat payment research and development.

In addition to the positive influences, we also found some interesting results from this experiment. The first interesting result is that social interaction does not have a significant effect on perceived usefulness, while social interaction has direct influences on trust and perceived enjoyment, both of which significantly affect the perceived usefulness. Previous studies have suggested that the perceived usefulness of an online payment was supported by the user experience of engaging in the financial trade online [15]. While in WeChat payment, the online trade is not limited to friends, which means that when the transaction occurs with a friend does not significantly increase the user experience and it is likely to be related to the WeChat payment tool itself. However, the relationships of friends can increase the number of trades directly, and a strong attitude of trust can increase the use frequency of mobile payment services [11]. It could be concluded that social interaction has an indirect influence on perceived usefulness. Second, trust does not stand on the same level as revealed in previous studies [68], [63]. Although it has a positive 
influence on perceived usefulness, the effect is only intermediate. To determine the reason for this result, we observed the eliminated data from the responders who never used the WeChat payment service. We find that lower trust is the reason why many people do not choose to use this service. The most popular claim is that they do not believe that E-payments are secure, which means trust prevents them from participating [44]. Since in the analysis data, all informants are users of WeChat payment, they chose to trust the WeChat platform and its security policy and then chose to use the service and do not consider the trust factor significant. Therefore, their perceived usefulness is not affected as much by trust as other uncertain factors.

This proposed extended TAM model has several practical and theoretical implications for researchers and engineers to develop popular mobile social payment services. This study provided some in-depth analysis of the popularity of WeChat payment in China that can then be applied to the development of the E-commerce industry. Based on WeChat payment in China's rapid development and popularization, this paper analyses in-depth the influencing factors of user behaviour in combination with product features. It is argued that social interaction can bring more opportunities for mobile services, which is also verified by other mobile applications, such as games and E-learning. The mobile services should provide an excellent social interaction experience to encourage users to share their fun.

\subsection{Limitations and Future Research}

Similar to other research, there are several limitations in this study which deserve future effort to address. First of all, the sample group source and calculation method of our data will lead the limitation of the conclusion and the difficulty of reappearance. There are many researches on the model calculation methods used in this kind of qualitative analysis [56]. But for the mobile applications like WeChat which are not open data interfaces, questionnaire survey and TAM are still good way for the qualitative analysis. The purpose of our study is to provide a preliminary study of the advantages of WeChat payment for rapid development, thus to serve as a reference for other technical promotion. In the subsequent quantitative study, we will consider increasing the data size and objectivity, adding machine learning and other computational methods to give more and more meaningful conclusions. The major issue is related to the users of WeChat payment. The questionnaire in this research is in Chinese and all responses are from Mainland China. Thus, the results of this study may be difficult to generalize to other contexts. It would be interesting to extend this work to an international context and perhaps consider other social networks. Credit cards that are popular in foreign financial markets are far less popular in China than mobile payments. It would be interesting to compare these different financial models with different cultural backgrounds. Moreover, the proposed model and the questions of the investigation mainly focus on the usage intention of using the WeChat payment service, and the results revealed the factors and their influence for people to use the WeChat payment or not. However, usage continuation is also important for an application to survive in the market. It would be meaningful to excavate the factors regarding continuity in future research. Furthermore, the proposed model focuses much more on social factors, rather than the cooperation between different services and companies. This phenomenon is also a character of the WeChat payment service, which also deserves future study.

\section{Conclusion}

The development of social networks and mobile devices has brought several innovations to our daily life. A typical example is WeChat payment, which is built on the most popular mobile social networks in China and now has attracted much attention from E-commerce and other applications. In this research, we use WeChat payment as a case to study the determinants beneath this popular application. To this end, the technology acceptance model is employed and some amending predictors are integrated from the social and mobile perspectives. After analysis of an online survey questionnaire, some interesting findings are revealed. It is believed this research provides insights into relevant for social-based mobile online payments to understand the adoption behaviour and further improve their services. Our research has found that the key advantage of WeChat payment to attract users is to integrate social factors into the application. Relying on WeChat convenient social platform, users can easily and effectively meet the demands of financial interaction in daily life. At the same time, WeChat payment innovative brings various social games and activities, enhancing the users' enjoyment of using mobile payment services. With the successful experience of WeChat payment, for other information technology and products, they can be combined with existing social mobile network applications, reducing the cost, enhancing the social interaction, thereby improving technology promotion rate and utilization rate.

\section{Acknowledgements}

This research was partially supported by the National Natural Science Foundation of China (No. 61472021).

\section{References}

[1] F. Abdullah, R. Ward, and E. Ahmed, Investigating the influence of the most commonly used external variables of TAM on students' Perceived Ease of Use (PEOU) and Perceived Usefulness (PU) of e-portfolios, Computers in Human Behavior, vol. 63, pp. 75-90, 2016. 
[2] A. M. Ahmed, T. Qiu, F. Xia, B. Jedari, and S. Abolfazli, Event-based mobile social networks: Services, technologies, and applications, IEEE Access, vol. 2, pp. 500-513, 2014

[3] R. AlGhamdi, S. Drew, and S. Alkhalaf, Government initiatives: The missing key for e-commerce growth in KSA CoRR, abs/1211.2398, 2012.

[4] A. Bakhtiar, Employee perceptions to standards capability: A cross second order confirmatory factors analysis in manufacturing firms-Indonesia, in Proceedings of 2013 IEEE Business Engineering and Industrial Applications Colloquium, Langkawi, Malaysia, pp. 44-49, 2013.

[5] G. Baptista and T. Oliveira, Understanding mobile banking: The unified theory of acceptance and use of technology combined with cultural moderators, Computers in Human Behavior, vol. 50, pp. 418-430, 2015.

[6] A. Bensoussan, M. K. Kantarcioglu and S. C. Hoe, A trust-score-based access control in assured information sharing systems: An application of financial credit risk score models, Risk and Decision Analysis, vol. 5, no. 2-3, pp. 129-138, 2014.

[7] S. H. Burton, R. G. Morris, C. G. Giraud-Carrier, J. H. West, and R. Thackeray, Mining useful association rules from questionnaire data, Intelligent Data Analysis, vol. 18, no. 3, pp. 479-494, 2014.

[8] China Internet Watch. (2013, August) Tencent unveiled big ambition with WeChat payment. China Internet Watch. [Online]. Available: http://www.chinainternetwatch.com/3386/tencent-wechat-payment/

[9] China Internet Watch. (2015, February) Echat, Weibo or Alipay? who won Hongbao war in 2015? [Online]. Available: http://www.chinainternetwatch.com/12424/hongbao-war-2015/

[10] Curiosity China. (2015, June) 2015 WeChat User Data Report. [online]. Available: http://news.ittime.com.cn/news/news 4840.shtml/

[11] S. Conner, The effect of social distance on consumer perceptions of a business when there is a breach of credit/debit card security, Academy of Business Research, Vol. 1, pp. 16-34, 2013.

[12] F. D. Davis, Perceived usefulness, perceived ease of use, and user acceptance of information technology, MIS Quarterly, vol. 13, no. 3, pp. 319-340, 1989.

[13] F. D. Davis, R. P. Bagozzi, and P. R. Warshaw, User acceptance of computer technology: A comparison on two theoretical models, Management Science, vol. 35, no. 8, pp. 729-736, 1989.

[14] O. Dele-Ajayi, R. Strachan, J. Sanderson, and A. Pickard, A modified TAM for predicting acceptance of digital educational games by teachers, in Proceedings of 2017 IEEE Global Engineering Education Conference, Athens, Greece, 2017, pp. 961-968.

[15] M. A. E. Fadl, B. Abbey, and K. S. Choi, Effect of IT trading platform on financial risk-taking and portfolio performance, in Proceedings of 48th Hawaii International Conference on System Sciences, Hawaii, USA, pp. 3298-3306, 2015.

[16] C. Gan, The impact of use context on mobile payment user adoption: An empirical study in China, in Proceedings of 15th Wuhan International Conference on E-Business, Wuhan, China, 2016.

[17] L. Gao and Y. Guo, Evaluating the operational risk of Chinese personal e-banking, in Proceedings of 2010 International Conference on E-Business and E-Government, Guangzhou, China, 2010, pp. 584-587.

[18] D. Gefen, E-commerce: the role of familiarity and trust, Omega, vol. 28, no. 6, pp. 725-737, 2000.

[19] A. Guillén, L. J. Herrera, H. Pomares, I. Rojas, and F. J. Liébana-Cabanillas, Decision support system to determine intention to use mobile payment systems on social networks: A methodological analysis, International Journal of Intelligent System, vol. 31, no. 2, pp. 153-172, 2016.

[20] S. Gupta, Choosing Web 2.0 tools for instruction: An extension of task-technology fit, International Journal of Information and Communication Technologies in Education, vol. 10, no. 2, pp. 25-35, 2014.

[21] R. Gupta and T. H. Falk, Latent factor analysis for synthesized speech quality-of-experience assessment, Quality \& User Experience, vol. 2, no. 2, 2017.

[22] J. F. Hair, W. C. Black, B. J. Babin, and R. E. Anderson, Multivariate Data Analysis, 7th ed., Upper Saddle River: Pearson, 2009

[23] Y. He, Y. Shi, and A. He, Research on online payment mode of e-commerce, in Proceedings of 2010 IEEE International Conference on Software Engineering and Service Sciences, Beijing, China, pp. 312-315, 2010.

[24] X. Hua, W. Qi, and S. Zhang, Research on undergraduates' perception of WeChat acceptance, in Proceedings of 11th IEEE International Conference on e-Business Engineering, Guangzhou, China, pp. 61-67, 2014.

[25] D. B. Humphrey and R. Hunt, Cost savings from check 21 electronic payment legislation, Journal of Money, Credit and Banking, vol. 45, no. 7, pp. 1415-1429, 2013.

[26] C. Kim, M. Mirusmonov, and I. Lee, An empirical examination of factors influencing the intention to use mobile payment, Computers in Human Behavior, vol. 26, no. 3, pp. 310-322, 2010.

[27] A. Klein, H. Ahlf, and V. Sharma, Social activity and structural centrality in online social networks, Telematics and Informatics, vol. 32, no. 2, pp. 321-332, 2015.

[28] T. K. Koh, M. Fichman, and R. E. Kraut, Trust across borders: Buyer-supplier trust in global business-tobusiness e-commerce, Journal of the AIS, vol. 13, no. 11, 2012.

[29] M. Koufaris, Applying the technology acceptance model and flow theory to online consumer behavior, Information Systems Research, vol. 13, no. 2, pp. 205-223, 2002.

[30] S. Kucukemiroglu and A. Kara, Online word-of-mouth communication on social networking sites: An empirical study of Facebook users, International Journal of Commerce and Management, vol. 25, no. 1, pp. 2-20, 2015.

[31] P. Legris, J. Ingham, P. Collerette, Why do people use information technology? A critical review of the technology acceptance model, Information \& Management, vol. 40, no. 3, pp. 191-204, 2003.

[32] J. Li, J. L. Liu and, H. Y. Ji, Empirical study of influence factors of adaption intention of mobile payment based on tam model in China, International Journal of U- \& E-Service, Science \& Technology, vol. 7, no. 1, pp. 119132, 2014. 
[33] F. J. Liébana-Cabanillas, J. Sánchez-Fernández, and F. Muñoz-Leiva, The moderating effect of experience in the adoption of mobile payment tools in virtual social networks: The m-payment acceptance model in virtual social networks (MPAM-VSN), International Journal of Information Management, vol. 34, no. 2, pp. 151-166, 2014.

[34] Y. Liu and H. Li, Exploring the impact of use context on mobile hedonic services adoption: An empirical study on mobile gaming in China, Computers in Human Behavior, vol. 27, no. 2, pp. 890-898, 2011.

[35] P. Lubomski and H. Krawczyk, Clustering context items into user trust levels, in Proceedings of 11th International Conference on Dependability and Complex Systems, Brunów, Poland, 2016, pp. 333-342.

[36] S. B. MacKenzie, P. M. Podsakoff, and N. P. Podsakoff, Construct measurement and validation procedures in MIS and behavioral research: Integrating new and existing techniques, MIS Quarterly, vol. 35, no. 2, pp. 293$334,2011$.

[37] T. P. Mackey and J. Ho, Exploring the relationships between web usability and students' perceived learning in web-based multimedia (WBMM) tutorials, Computers \& Education, vol. 50, no. 1, pp. 386-409, 2008.

[38] N. Mallat, Exploring consumer adoption of mobile payments-a qualitative study, The Journal of Strategic Information Systems, vol. 16, no. 4, pp. 413-432, 2007

[39] N. Mallat, M. Rossi, V. K. Tuunainen, and A. Oörni, The impact of use context on mobile services acceptance: The case of mobile ticketing, Information \& Management, vol. 46, no. 3, pp. 190-195, 2009.

[40] T. Mantoro, A. Milišić, and M. Ayu, Online payment procedure involving mobile phone network infrastructure and devices, in Proceedings of 2011 International Conference on Multimedia Computing and Systems, Ouarzazate, Morocco, 2011, pp. 1-6.

[41] V. Marinkovic and Z. Kalinic, Antecedents of customer satisfaction in mobile commerce: Exploring the moderating effect of customization, Online Information Review, vol. 41, no. 2, pp. 138-154, 2017.

[42] F. Martin and J. Ertzberger, Here and now mobile learning: An experimental study on the use of mobile technology, Computers \& Education, vol. 68, pp. 76-85, 2013

[43] S. S. Martín, B. López - Catalán, and M. A. Ramón - Jerónimo, Factors determining firms' perceived performance of mobile commerce, Industrial Management \& Data Systems, vol. 112, no. 6, pp. 946-963, 2012.

[44] J. McNeish, Consumer trust and distrust: Retaining paper bills in online banking, International Journal of Bank Marketing, vol. 33, no. 1, pp. 5-22, 2015.

[45] M. Mohamadi and T. Ranjbaran, Effective factors on the success or failure of the online payment systems, focusing on human factors, in Proceedings of 7th International Conference on e-Commerce in Developing Countries: With Focus on e-Security, Kish Island, Iran, 2013, pp. 1-12.

[46] A. R. Montazemi and H. Q. Saremi, Factors affecting internet banking pre-usage expectation formation, in Proceedings of 46th Hawaii International Conference on System Sciences, Hawaii, USA, 2013, pp. 4666-4675.

[47] F. Muñoz-Leiva, S. Climent-Climent, and F. Liébana-Cabanillas, Determinants of intention to use the mobile banking apps: An extension of the classic TAM model, Spanish Journal of Marketing - ESIC, vol. 21, no. 1, pp. 25-38, 2017.

[48] T. Oliveira, M. A. Thomas, G. Baptista, and F. Campos, Mobile payment: Understanding the determinants of customer adoption and intention to recommend the technology, Computers in Human Behavior, vol. 61, pp. 404-414, 2016

[49] S. M. Pi, H. L. Liao, and H. M. Chen, Factors that affect consumers trust and continuous adoption of online financial services, International Journal of Business and Management, vol. 7, no. 9, pp. 108-119, 2012.

[50] Y. Qu, W. Rong, Y. Ouyang, H. Chen, Z. Xiong, Social aware mobile payment service popularity analysis: The case of WeChat payment in China, in Proceedings of 9th Asia-Pacific Services Computing Conference, Bankok, Thailand, pp. 289-299, 2015.

[51] K. Sailer and I. McCulloh, Social networks and spatial configuration - how office layouts drive social interaction, Social Networks, vol. 34, no. 1, pp. 47-58, 2012.

[52] H. B. Santoso, R. Y. K. Isal, T. Basaruddin, L. Sadira, and M. Schrepp, Research-in-progress: User experience evaluation of student centered e-learning environment for computer science program, in Proceedings of 3rd International Conference on User Science and Engineering, Shah Alam, Malaysia, pp. 52-55, 2014.

[53] P. G. Schierz, O. Schilke, and B. W. Wirtz, Understanding consumer acceptance of mobile payment services: An empirical analysis, Electronic Commerce Research and Applications, vol. 9, no. 3, pp. 209-216, 2010.

[54] M. J. Schniederjans, Q. Cao, J. H. Triche, E-commerce Operations Management. Singapore: World Scientific, 2013.

[55] B. Singh and K. S. Jasmine, A new architecture of mobile payment system through social media network, Journal of Electronic Commerce in Organizations, vol. 12, no. 3, pp. 60-74, 2014.

[56] R. Sharma, P. Yetton, and J. Crawford, Estimating the effect of common method variance: The method-method pair technique with an illustration from TAM research. MIS Quarterly, Vol. 33, No. 3, pp. 473-490, 2009.

[57] A. M. Soares and J. C. Pinho, Advertising in online social networks: The role of perceived enjoyment and social influence, Journal of Research in Interactive Marketing, vol. 8, no. 3, pp. 245-263, 2014.

[58] L. Staphorst, L. Pretorius, and T. W. Pretorius, Structural equation modelling based data fusion for technology forecasting: A national research and education network example, in Proceedings of 2014 Portland International Conference on Management of Engineering Technology, Kanazawa, Japan, pp. 2908-2917, 2014

[59] A. Tamersoy, Graph-based algorithms and models for security, healthcare, and finance, Ph.D. dissertation, School of Computational Science and Engineering, Georgia Institute of Technology, Atlanta, GA, USA, 2016.

[60] Tencent Technology. (2017, February) WeChat spring festival data report. [Online]. Available: http://tech.qq.com/a/20170203/010341.htm 
[61] P. Wang. (2017, May) The first quarter of 2017 China's third party mobile payment market monitoring report. Analysys. [Online]. Available: https://www.analysys.cn/analysis/22/detail/1000762/

[62] Y. S. Wang, H. H. Lin, and Y.-W. Liao, Investigating the individual difference antecedents of perceived enjoyment in students' use of blogging, British Journal of Educational Technology, vol. 43, no. 1, pp. 139-152, 2012.

[63] J. Weisberg, D. Te'eni, and L. A. Russo, Past purchase and intention to purchase in e-commerce: The mediation of social presence and trust, Internet Research, vol. 21, no. 1, pp. 82-96, 2011.

[64] B. Williams, A. Onsman, and T. Brown, Exploratory factor analysis: A five-step guide for novices, Journal of Emergency Primary Health Care, vol. 8, no. 3, pp. 1-13, 2012.

[65] M. Wolgast, What does the acceptance and action questionnaire (AAQ-II) really measure? Behavior Therapy, vol. 45, no. 6, pp. 831-839, 2014

[66] W. Xie, Social network site use, mobile personal talk and social capital among teenagers, Computers in Human Behavior, vol. 41, pp. 228-235, 2014.

[67] $\mathrm{H}$. Xu, The effect of perceived security on consumers intent to use: Satisfaction and loyalty to m-commerce in China, Journal of Electronic Commerce in Organizations, vol. 11, no. 4, pp. 37-51, 2013.

[68] Q. Yang, C. Pang, L. Liu, D. C. Yen, and J. M. Tarn, Exploring consumer perceived risk and trust for online payments: An empirical study in China's younger generation, Computers in Human Behavior, vol. 50, pp. 9-24, 2015.

[69] D. Yang, H. Wang, Y. Ren, and J. Wang, Mobile payment pattern based on multiple trusted platforms - China case, in Proceedings of 9th International Conference on Mobile Business and 9th Global Mobility Roundtable, Athens, Greece, 2010, pp. 353-362.

[70] S. Yang, Y. Lu, S. Gupta, Y. Cao, and R. Zhang, Mobile payment services adoption across time: An empirical study of the effects of behavioral beliefs, social influences, and personal traits, Computers in Human Behavior, vol. 28, no. 1, pp. 129-142, 2012.

[71] F. Zafar, R. Ishaque and M. Javaid, Use of ICT and e-commerce towards achieving competitive advantages, European Journal of Research and Reflection in Management Sciences, vol. 2, no. 1, pp. 1-10, 2014.

[72] Y. Zhang and W. Duan, Envelopment-competition pattern of e-business platform - insights from the competition among Taobao, Baidu and Tencent, in Proceedings of 5th International Conference on Business Intelligence and Financial Engineering, Lanzhou, Gansu, China, 2012, pp. 51-55.

[73] K. Zhang, X. Liang, X. Shen, and R. Lu, Exploiting multimedia services in mobile social networks from security and privacy perspectives, IEEE Communications Magazine, vol. 52, no. 3, pp. 58-65, 2014.

[74] T. Zhou, An empirical examination of continuance intention of mobile payment services, Decision Support Systems, vol. 54, no. 2, pp. 1085-1091, 2013.

[75] T. Zhou, An empirical examination of initial trust in mobile payment, Wireless Personal Communications, vol. 77 , no. 2, pp. 1519-1531, 2014. 